\title{
First Detection of Phytophthora infestans, the Causal Agent of Late Blight Disease of Potato Solanum tuberosum L. In Northern State, Sudan
}

\author{
Altaf M. Elhassan* \\ Agricultural Research Corporation (ARC) - Merowe Research Station (MRS), Sudan \\ *Corresponding author
}

\begin{tabular}{|c|c|}
\hline & B S T R A C T \\
\hline $\begin{array}{l}\text { Solanum } \\
\text { tuberosum L } \\
\text { Phytophthora } \\
\text { infestans, } \\
\text { Merowe, } \\
\text { Sudan, } \\
\text { potato }\end{array}$ & \multirow{3}{*}{$\begin{array}{l}\text { A serious fungal disease of potato (Solanum tuberosum L.) was observed in } \\
\text { Merowe and Eldebba localities, Northern state. The symptoms include Lesions } \\
\text { begin as indefinite, water-soaked spots that enlarge rapidly into pale green to } \\
\text { brownish-black lesions and can cover large areas of the leaf. During wet weather, } \\
\text { lesions on the abaxial surface of the leaf vered with a gray to white moldy growth } \\
\text { on the undersides of larger lesions, a ring of moldy growth of the pathogen is often } \\
\text { visible. As the disease progresses, the foliage turns yellow and then brown, curls, } \\
\text { shrivels, and dies. In stem dark brown or black lesions develop in the cortical } \\
\text { tissue near the soil line. The fungus, Phytophthora infestans, (Mont). de Bary) was } \\
\text { consistently isolated from the affected seedlings and its pathogencity was } \\
\text { confirmed in the seedlings of the potato cv. Belleni. Symptoms were reproduced by } \\
\text { injected stem with pathogen suspension. This study reports for the first time the } \\
\text { presence of Phytophthora infestans (Mont). de Bary) in the Northern Sudan } \\
\text { causing late blight disease in potato. }\end{array}$} \\
\hline Article Info & \\
\hline & \\
\hline
\end{tabular}

\section{Introduction}

Potato (Solanum tuberosum L is the most important food crop in the world after wheat, rice, and maize. Its production represents half of world's annual output of all root tubers (CPC, 2005). Potato was introduced in the Sudan in 1920's (Abdalla and AlShafie, 1983). Main production areas are River Nile State, Khartoum State, Southern Darfur state and Northern State. The area under production rose steadily from 39,000 feddan in 2000 to 48,000 in 2004 then dropped to 36,870 feddan in 2007 (Al Basheer, 2008). The drop was attributed to the heavy infestation of one of the most important production area with Orobanche ramosa. Production also increased from 3600 tons in 2000 to 272,000 tons in 2000 to 336,000 tons in 2004. Potato is vulnerable to infected with some distractive diseases which are responsible for decline and considerable losses in yield (Baldo,2010). Acute symptoms observed in Merowe Locality (New amri scheme) and Eldebba locality (New hamadab scheme), where the potato is grown under pivot irrigation system and in small potato farm at Abudoom, Elgurier, Elzoma and Elarak, Merowe locality.

The objectives of this study were to identify the causal agents of blight disease of potato 
Solanum tuberosum L. observed in Northern state Merowe and Eldebba localities

\section{Materials and Methods}

\section{Preparation of plant material}

From different locations six infected potato Solanum tuberosum L samples (leaves, stem) were collected in paper bags and brought to the laboratory for the isolation and identification of the causal agents.

\section{Isolation of the causal agents}

Isolation was done from diseased tissues such as stem, leaves. Small infected tissues were washed in tap water to remove adhering soil particles, cut into small pieces of about $0.3 \mathrm{~cm}$ surface disinfected for $2 \mathrm{~min}$ and left to dry on sterilized filter paper and then plated on petri dishes containing water agar (WA) medium.Then transferred to selective media Corn meal agar medium (CMA) and incubated at $25^{\circ}$ for 10 days. Fungi colonies were examined. Identification of fungi based on the taxonomic keys of Waterhouse (1963) and Stamps et al., (1990).

\section{Pathogenicity test}

The pathogenicitytest was conducted under laboratory conditions. Seeds of potato variety Belleni were surface sterilized for 2 min with $0.5 \%$ sodium hypochlorite then washed with SDW before sowing in plastic pots containing sand and clay at 1:2 ratio (five seeds of Belleni variety) replicated three times. The pots were kept in the nursery. Sporangial suspension of the fungus was prepared by flooding the plates with distilled water and harvesting the spores a few hours after flooding, small drop of water containing $10^{4}$ sporangia/mL is placed. Small wound in stem was made into 21 old days plant by sterilized a scalpel then $10^{4}$ sporangia/mL injected for each plant and the control was injected with sterilized water only and all seedlings covered with polythene bags to create a moist and humid environment. The bag is removed 48 hours after inoculation. Disease symptoms observed and recorded.

\section{Results and Discussion}

\section{Symptoms of blight disease}

Symptoms observed were black/brown lesions (Figures 1,2) on leaves and stems that may be small at first and appear watersoaked or have chlorotic borders, but soon expand rapidly and become necrotic. The pathogen produced sporangia and sporangiophores on the lower surface of infected tissue.

Fig.1 Dark brown or black lesions in stem

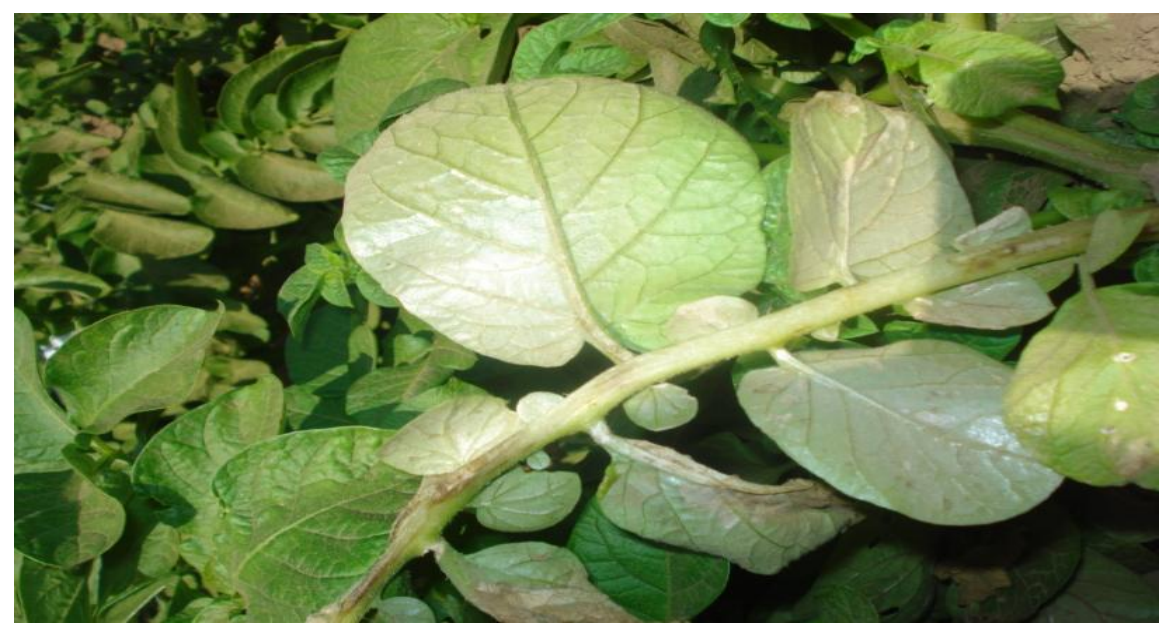


Fig.2 visible white growth on a baxial (lower) surfaces of leaves

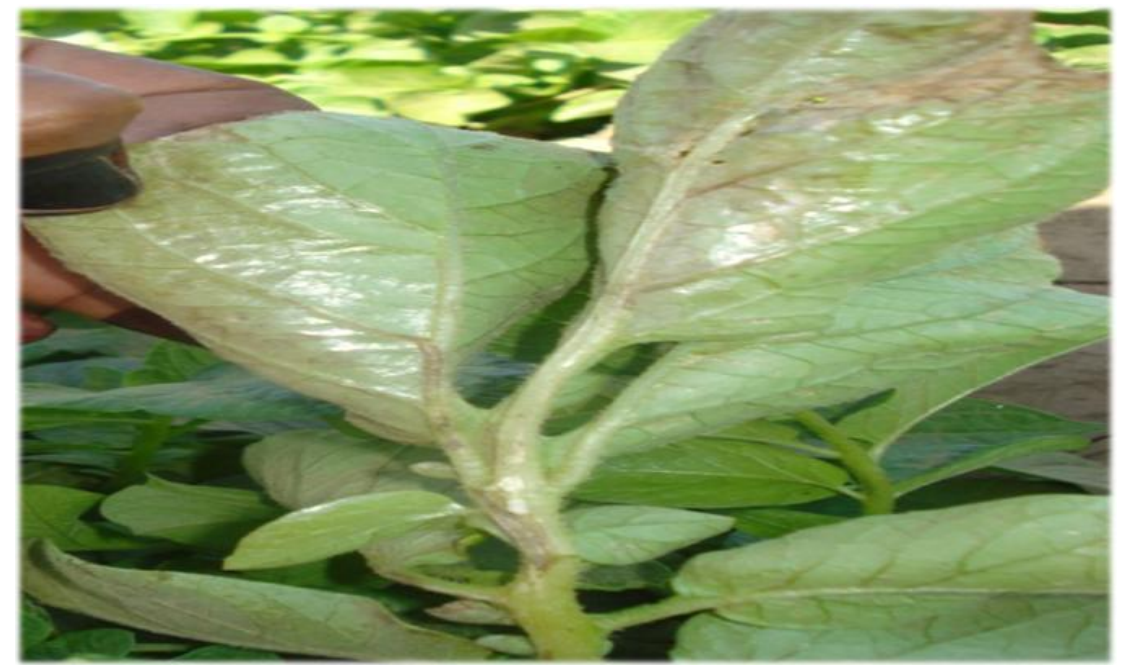

Fig.3 Black/brown lesions) on leaves and stem

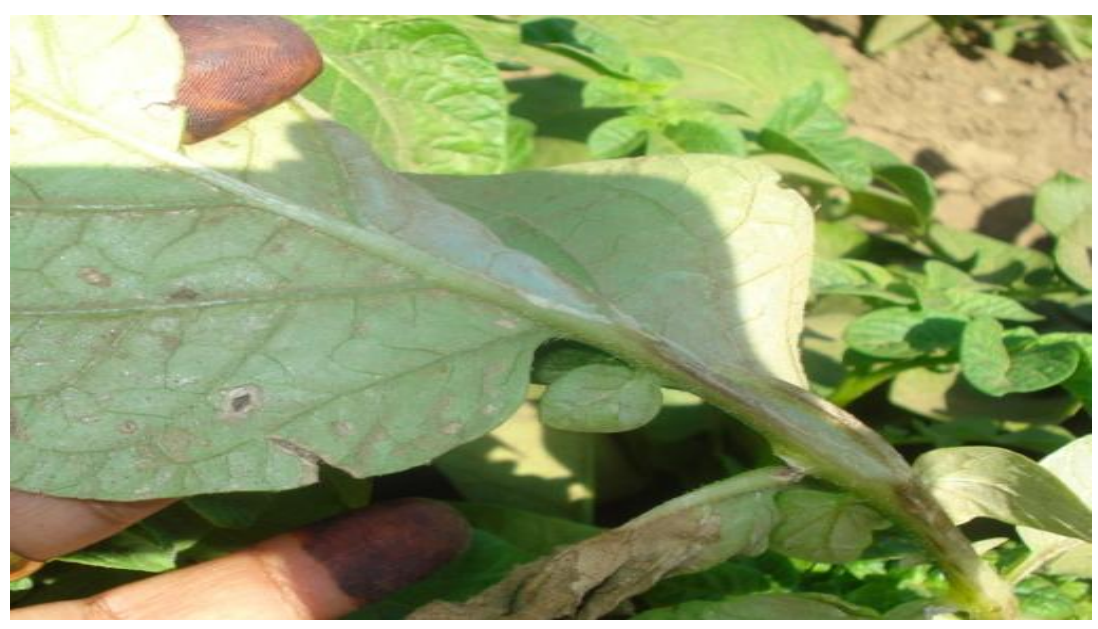

Fig.4 Genral decline in Belleni variety in open field

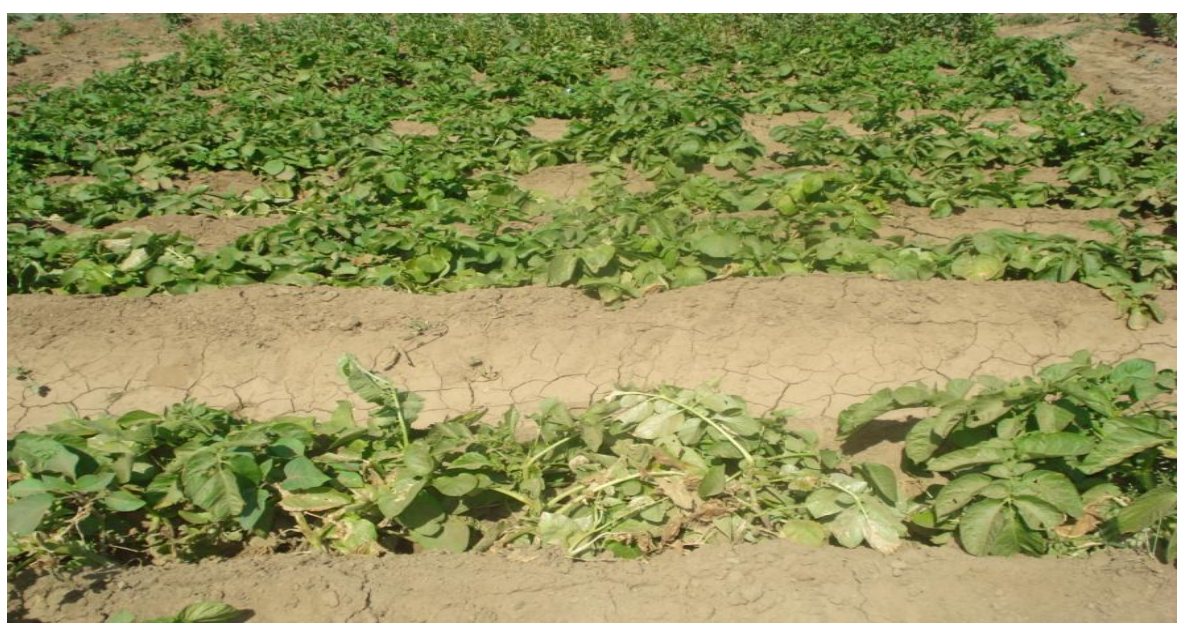


Fig.5 Phytophthora infestans (Mont). de Bary) sporongia

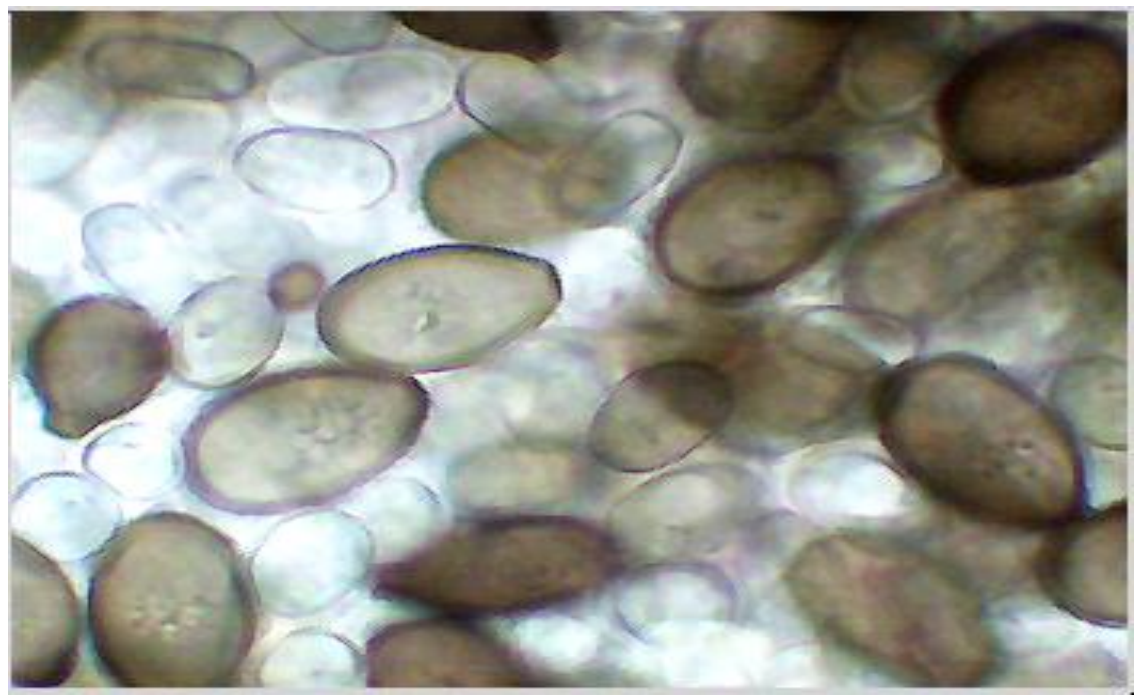

This sporulation results in a visible white growth at the leading edge of lesions on a baxial (lower) surfaces of leaves (Figure3). As many lesions accumulate, the entire plant can be destroyed in only a few days after the first lesions are observed (Figure 4). In stem dark brown or black lesions develop in the cortical tissue near the soil line. Expanded lesions often girdle the stem and give rise to wilting and death of the upstream branches and leaves. Tuber infections are characterised by patches of brown to purple discoloration on the potato skin. Cutting just below the skin reveals a dark reddish brown, dry corky rot.

\section{Isolation and Identification of the causal agent}

The identification of the fungus isolate was based on in vitro culture characteristics on Corn meal Agar medium (CMA) and morphology (sporangia and sporangiophores).

Morphological studies of the causal agent was iniaitialey carried with corn meal agar incubation at $23-25 \mathrm{c}^{\circ}$. The mycelium colony gradually changes to white and later to grey and black after 15 days. The spores was in oval shape (Figur5) In vitro Lab investigation using Corn meal agar medium (CMA), showed great numbers of hyaline zoospores vary in form and dimension on the same culture.

\section{Pathogenicity test}

The early symptoms observed on the stem and old leaves typically seen 10-14 days after inoculation seedlings of the potato varieties Belleni appeared as brown lesion and brown spots, which later resulted in drying and general death of the seedling. Pathogenicity and biological performance of the isolated fungus, the causal agent was identified as Phytophthora infestans (Mont). de Bary) constituting by that the first report of Late blight on potato in Northern Sudan Merowe and Eldebba localities.

\section{References}

Abdalla, A.A., Al Shafie, B. 1983. Yield experiments with potato in the arid tropics of the Sudan. Sudan Agri. J., 10: 5-18.

Al Basheer, M.A. 2008. The development in 
the quality and Quantity of horticultural crops for export. A thesis presented to the Military Academy for the degree of Diploma in Management.

Baldo, N.H., S.M. Elhassan and M.M. Elballa. 2010. Occurrence of Viruses Affecting Potato Crops in Khartoum State, Sudan. Potato Res., 53(1): 61-67.

CPC 2005. The Crop Protection Compendium, $\mathrm{CAB}, \quad$ International walling Ford, U.K. CAB International. Stamps, D.J., G.M. Waterhouse, F.J. Newhook, and G.S. Hall. 1990. Revised tabular key to the species of Phytophthora, Institute of Mycology Paper 162: Agricultural Bureau of International Mycology Institute.

Waterhouse, G.M. 1963. Key to the species of Phytophthora de Bary, Mycological Papers No. 92: Commonwealth Mycological Institute, Kew, Surrey, England.

\section{How to cite this article:}

Altaf M. Elhassan. 2016. First Detection of Phytophthora infestans, the Causal Agent of Late Blight Disease of Potato Solanum tuberosum L. In Northern State, Sudan. Int.J.Curr.Microbiol.App.Sci. 5(7): 387-391. doi: http://dx.doi.org/10.20546/ijcmas.2016.507.042 